\title{
QUALIDADE MICROBIOLÓGICA DE POLPAS DE AÇAÍ CONGELADAS
}

\author{
GIANFREDO, Gabriel de Morais ${ }^{1}$
}

MARTINS, Eduardo da Silva ${ }^{2}$

\author{
Recebido em: 2020.03.19 \\ Aprovado em: 2020.06 .25 \\ ISSUE DOI: $10.3738 / 1982.2278 .3762$
}

\begin{abstract}
RESUMO: O consumo de açaí no Brasil vem crescendo consideravelmente nos últimos anos, fato que pode ser observado pela grande expansão das açaiterias no país. O presente trabalho teve como objetivo avaliar a qualidade microbiológica de polpas de açaí congeladas, comercializadas no município de Frutal, MG. Foram coletas mensalmente 5 amostras durante 6 meses, em diferentes estabelecimentos, totalizando 30 amostras. A qualidade microbiológica das amostras foi avaliada em relação aos seguintes microrganismos: coliformes totais, coliformes termotolerantes, bactérias aeróbias mesófilas, bolores e leveduras e Salmonella sp. Das 30 amostras de polpas de açaí avaliadas, observou-se que $21(70 \%)$ estavam dentro dos padrões da legislação para todos os microrganismos avaliados e $9(30 \%)$ estavam fora dos padrões, por apresentarem contagem de bolores e leveduras acima dos limites estabelecidos. Os resultados indicam falhas em alguma etapa da produção, processamento ou na manipulação do produto nos estabelecimentos que apresentaram amostras insatisfatórias. Nestes estabelecimentos em que foram encontradas amostras fora dos padrões, torna-se fundamental verificar as possíveis causas, a fim de se evitar doenças transmitidas pela ingestão da polpa de açaí.
\end{abstract}

Palavras-chave: Alimento. Bactérias. Fungos.

\section{MICROBIOLOGICAL QUALITY OF FROZEN AÇAÍ PULPS}

SUMMARY: The consumption of açaí in Brazil has been growning considerably in last years, a fact that can be observed by the great expansion of açaí in the country. This study aimed to evaluate the microbiological quality of frozen açaí pulps, marketed in the municipality of Frutal, MG. Five samples were collected monthly for 6 months, in different establishments, totaling 30 samples. The microbiological quality of the samples was evaluated in relation to the following microorganisms: total coliforms, thermotolerant coliforms, aerobic mesophilic bacteria, molds and yeasts and Salmonella sp. Of the 30 samples of açaí pulp evaluated, it was observed that $21(70 \%)$ were within the standards of the legislation for all the microorganisms evaluated and $9(30 \%)$ were outside the standards, as they had mold and yeast count above established limits. The results indicate failures in some stage of production, processing or product handling in establishments that presented unsatisfactory samples. In these establishments where nonstandard samples were found, it is essential to check the possible causes, in order to avoid foodborne diseases, resulting from the ingestion of açaí pulp.

Keywords: Food; Bacteria; Fungus.

\section{INTRODUÇÃO}

O açaí (Euterpe oleracea Mart.) é o fruto da palmeira conhecida como açaizeiro, uma espécie nativa das várzeas da região amazônica. Nos últimos anos, a demanda por açaí tem crescido gradativamente nos mercados nacional e internacional, pelo seu caráter energético e nutritivo e por conferir propriedades funcionais aos seus consumidores, em virtude do seu alto teor de fibras e antioxidantes (MARINHO et al., 2018).

\footnotetext{
${ }^{1}$ Graduando em Engenharia Agronômica

${ }^{2}$ Departamento de Ciências Exatas e da Terra, área de Microbiologia Aplicada.
} 
A polpa desse fruto tem sido objeto de alguns estudos em decorrência do seu valor nutritivo e sensorial, sendo inclusive considerada como um alimento funcional devido ao seu grande conteúdo de antocianinas, pigmentos responsáveis pela coloração característica do fruto. No mercado externo, o açaí é apreciado como uma bebida exótica, enquanto que no Brasil, como bebida energética, sendo muito consumido na forma de polpa congelada pronta para consumo, especialmente como frapês ou com xarope de guaraná e granola, na chamada "tigela de açaí" (CEDRIM; BARROS; NASCIMENTO, 2017; ALMICO et al., 2018).

Os principais fatores que propiciam a contaminação microbiológica do açaí são: o substrato é propício para o crescimento dos contaminantes (não ácido; a palmeira de açaí cresce em meios tropicais muito úmidos e quentes, o que é propício ao crescimento de microrganismos e de insetos; a falta de cuidado durante a colheita e o transporte da fruta; e a origem de contaminação suplementar pelo contato com superfícies contaminadas (ROGEZ et al., 2000).

Além da carga microbiana inicial alta dos frutos, a polpa de açaí pode ser contaminada por microbiota proveniente das condições higiênico-sanitárias dos equipamentos, ambiente de processamento, manipulação e exposição do produto, especialmente nos estabelecimentos com comercialização do tipo self-service (FARIA; OLIVEIRA; COSTA, 2012).

Dentre as alternativas de processos utilizados na elaboração e conservação da polpa, o congelamento é o procedimento mais utilizado. Entretanto, esta prática pode envolver problemas relacionados à quebra da cadeia de frio, durante a distribuição do produto, favorecendo o crescimento microbiano e comprometendo a qualidade da polpa (PEREIRA et al., 2006).

A Instrução Normativa $n^{\circ} 1$ (BRASIL, 2000) estabelece que a polpa de açaí e o açaí destinados ao consumo direto em embalagem de no máximo $1 \mathrm{~kg}$ deverão ser conservados através de processo físico, sendo proibido o uso de conservantes ou de corantes, com exceção do corante obtido do próprio fruto do açaí. É permitida a acidificação do produto, com ácido ascórbico ou ácido cítrico, para sua conservação à temperatura ambiente e o tratamento térmico de pasteurização é facultativo (CAYRES, PEREIRA; PENTEADO, 2017).

A resolução RDC n.12, 02/01/2001 (BRASIL, 2001), estabelece padrões microbiológicos para polpas de açaí sendo o valor máximo de $10^{2} \mathrm{UFC}^{-g^{-1}}$ para coliformes termotolerantes. A presença desse grupo de microrganismos em alimentos indica uma possível contaminação de origem fecal, assim como eventual ocorrência de enteropatógenos os quais podem trazer riscos à saúde dos consumidores (RIZZO-BENATO; GALLO, 2007).

Com relação à Salmonella, sp., a legislação não permite sua presença. Este gênero inclui várias espécies e sorotipos patogênicos para o homem e outros animais. Dentre os sorotipos, existem três grupos: a febre tifóide, causada por $S$. typhi, a febre entérica, cujo agente etiológico é a S. paratyphi e a infecção gastrointestinal, mais comum, causada S. enteritidis (MOURA, 2014). 
Quanto à presença de presença de bolores e leveduras, estes podem indicar falhas na produção, manipulação e/ou assepsia (FRANCO; LANDGRAF, 1996). Em polpas de açaí congeladas, a legislação prevê limite máximo de 5,0.10³ UFC/g (BRASIL, 2001).

No sentido de tornar o consumo do açaí seguro em nossa alimentação, pesquisas sobre as condições higiênico-sanitárias do produto são necessárias para que se possa avaliar se o processamento e/ou comercialização apresenta controle efetivo que atenda às características e à integridade do produto, bem como os parâmetros de qualidade para a saúde dos consumidores (ALMICO et al., 2018).

Diante deste contexto, este trabalho teve como objetivo avaliar a qualidade microbiológica de polpas de açaí congeladas, comercializadas no município de Frutal/MG, visando obter informações sobre a segurança do seu consumo.

\section{MATERIAL E MÉTODO}

\subsection{Amostras}

Foram analisadas mensalmente amostras de polpas de açaí congeladas provenientes de sorveterias e açaiterias da cidade de Frutal/MG. Foi coletada 1 amostra de 5 locais por mês, durante 6 meses, totalizando 30 amostras. Estas foram coletadas conforme comercializadas, em copos de plástico descartáveis, e em seguida levadas ao Laboratório de Microbiologia da Universidade do Estado de Minas Gerais, unidade de Frutal/MG. Após coletadas, as amostras foram acondicionadas em caixa térmica com gelo, para evitar qualquer alteração nas mesmas até sua chegada ao laboratório.

\subsection{Diluição das amostras para as análises microbiológicas}

Para a quantificação dos diferentes grupos microbianos, foram realizadas as diluições das amostras pesando-se $25 \mathrm{~g}$ de cada amostra, transferindo-a para frascos Erlenmeyer previamente esterilizados, contendo $225 \mathrm{~mL}$ de água peptonada $0,1 \%$ esterilizada, obtendo-se assim a diluição $10^{-1}$. A partir desta diluição foram feitas diluições em série até a obtenção da diluição $10^{-3}$, sempre transferindo $1 \mathrm{~mL}$ de cada diluição para tubos contendo $9 \mathrm{~mL}$ de água peptonada a $0,1 \%$.

\subsection{Análises microbiológicas}

As análises microbiológicas foram realizadas segundo a Resolução RDC $n^{\circ} 12$, de 02 de janeiro de 2001 (BRASIL, 2001), para determinação do Número Mais Provável (NMP) de coliformes totais e termotolerantes, Salmonella sp. e bolores e leveduras. Os resultados foram 
confrontados aos padrões da legislação ou então com a literatura especializada, para aqueles grupos microbianos para os quais não há limites incluídos na legislação.

Para a análise do Número Mais Provável (NMP) de coliformes termotolerantes, foi utilizada a técnica de tubos múltiplos como descrita no Standard Methods for the Examination of Water and Wastewater (APHA, 2012). Alíquotas de $1 \mathrm{~mL}$ de cada diluição foram inoculadas em três séries de três tubos contendo $9 \mathrm{~mL}$ de caldo Lauril Sulfato Triptose (LST), com tubo de Duhran invertido (teste presuntivo). Os tubos foram incubados a $35^{\circ} \mathrm{C}$ por $24-48$ horas. A partir dos tubos com leitura positiva (turvação e formação de gás), foram realizados os testes confirmativos para coliformes totais em Caldo Verde Bile Brilhante (CVBB) a $35^{\circ} \mathrm{C}$ por $24-48$ horas e coliformes termotolerantes em caldo Escherichia coli (EC) a $45,0^{\circ} \mathrm{C}$ por $24-48$ horas.

Para indicar a presença de bactérias Salmonella sp, foi feita a contagem de colônias presentes na placa. Foram colocadas alíquotas de $1 \mathrm{ml}$, das diluições da amostra com a água peptonada $0,1 \%$ em placas de petri com ágar Salmonella/Shigella, sendo a inoculação por plaqueamento em superfície. Posteriormente, foram incubadas em estufa a $35 \pm 1^{\circ} \mathrm{C}$ por $24 \mathrm{~h}$. e avaliado o crescimento ou não de colônias típicas no meio (SILVA et al., 2010).

A determinação de bolores e leveduras foi feita por semeadura em superfície, em meio Potato Dextrose Agar (PDA), o qual foi incubado a $25^{\circ} \mathrm{C}$, durante 7 dias. Os resultados foram expressos em Unidades Formadoras de Colônias por g de polpa (UFC.g ${ }^{-1}$ ).

\section{RESULTADO E DISCUSSÃO}

De todos os grupos de microrganismos avaliados, observou-se que o único parâmetro microbiológico fora dos padrões foi para a contagem de bolores e leveduras. A legislação permite ano máximo $5.10^{3}$ UFC.g $^{-1}$ destes microrganismos. Das 30 amostras avaliadas, 21 (70\%) apresentaram valores abaixo deste limite. Por outro lado, 9 (30\%) apresentaram valores superiores, estando assim em desacordo com a legislação e consequentemente impróprias para consumo. Das 14 sorveterias/açaiterias onde foram feitas coletas, 7 (50\%) não apresentaram nenhuma amostra imprópria, enquanto que as outras (50\%) apresentaram pelo menos uma amostra imprópria durante as coletas (Tabela 1).

Na primeira coleta, a contagem de bolores e leveduras foi superior à legislação em 4 dos 5 estabelecimentos, com valores entre $6,0.10^{3}$ a $9,8 \cdot 10^{4} \mathrm{UFC}^{-1}{ }^{-1}$. Na segunda coleta foi observado que dos 5 estabelecimentos, 1 apresentou uma amostra imprópria $\left(3,4.10^{5} \mathrm{UFC} \mathrm{g}^{-1}\right)$. Já na terceira coleta, as amostras de dois estabelecimentos, dentre os cinco avaliados, apresentaram contagens impróprias para bolores e leveduras $\left(9,6 \cdot 10^{3}\right.$ e $2,5 \cdot 10^{4}$ UFC.g- $\left.^{1}\right)$. Na quarta coleta, duas amostras estavam fora dos padrões para bolores e leveduras (apresentando contagens de 7,0.10 ${ }^{3}$ e 7,3.10 
UFC.g ${ }^{-1}$ ). Já nas coletas 5 e 6 , todas as amostras estavam dentro dos padrões, para todos os microrganismos avaliados (Tabela 1).

Com relação à contagem de bactérias aeróbias mesófilas, esta variou de ausente até no máximo de 2,7.10 ${ }^{5} \mathrm{UFC}^{-1}{ }^{-1}$ (Tabela 1). Não há padrão estabelecido na legislação para esse grupo em polpas de frutas congeladas, porém contagens muito elevadas em alimentos (geralmente acima de $10^{6} \mathrm{UFC}^{-g^{-1}}$ ) podem indicar falhas de higienização e/ou manipulação (FORSYTHE, 2002).

Para coliformes totais, não há limite estabelecido na legislação, mas altas contagens também podem indicar falhas de higiene. Porém, não foram observadas altas contagens nas amostras avaliadas, uma vez que a maioria não apresentou esse grupo ou apresentou valores

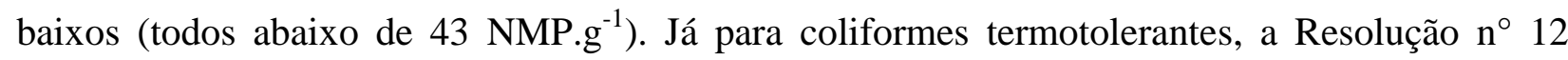
(BRASIL, 2001) estabelece para polpas de frutas com ou sem tratamento térmico, que a contagem de não pode ser superior a $100 \mathrm{NMP} . \mathrm{g}^{-1}$. Com relação aos coliformes termotolerantes, estes foram encontrados em apenas três amostras, porém com valores abaixo do limite estabelecido pela legislação (Tabela 1).

Quanto à Salmonella sp., nenhuma amostra apresentou sua presença, estando assim dentro dos padrões da legislação em relação a esse microrganismo (Tabela 1).

Tabela 1: Determinação de bactérias aeróbias mesófilas, bolores e leveduras, Salmonella sp., coliformes totais (CT) e coliformes termotolerantes (CTT) nas amostras de polpas de açaí.*

(Continua)

\begin{tabular}{|c|c|c|c|c|c|}
\hline Locais** & $\begin{array}{l}\text { Bactérias } \\
\left(\text { UFC.g }^{-1}\right)\end{array}$ & $\begin{array}{l}\text { Bolores e } \\
\text { leveduras } \\
\left(\text { UFC. }^{-1}\right)\end{array}$ & $\begin{array}{l}\text { Salmonella sp } \\
\quad\left(\mathrm{UFC}_{\mathrm{g}} \mathrm{g}^{-1}\right)\end{array}$ & $\begin{array}{c}\text { CT } \\
\left(\text { NMP.g }^{-1}\right)\end{array}$ & $\begin{array}{c}\text { CTT } \\
\left(\text { NMP.g }^{-1}\right)\end{array}$ \\
\hline \multicolumn{6}{|c|}{ COLETA 1} \\
\hline A & $5,3.10^{4}$ & $5,6.10^{4}$ & ausente & ausente & ausente \\
\hline B & $2,7.10^{5}$ & $9,8.10^{4}$ & ausente & 43 & 43 \\
\hline $\mathrm{C}$ & ausente & $3,5.10^{3}$ & ausente & ausente & ausente \\
\hline $\mathrm{D}$ & $5,0.10^{4}$ & $2,6.10^{4}$ & ausente & ausente & ausente \\
\hline $\mathrm{E}$ & $2,9.10^{3}$ & $6,0.10^{3}$ & ausente & ausente & ausente \\
\hline \multicolumn{6}{|c|}{ COLETA 2} \\
\hline $\mathrm{F}$ & $5,7.10^{3}$ & $3,4.10^{5}$ & ausente & ausente & ausente \\
\hline $\mathrm{G}$ & $2,0.10^{2}$ & $2,3.10^{3}$ & ausente & ausente & ausente \\
\hline $\mathrm{H}$ & $2,4.10^{3}$ & $1,8.10^{3}$ & ausente & ausente & ausente \\
\hline I & $5,0.10^{2}$ & $3,1.10^{3}$ & ausente & ausente & ausente \\
\hline $\mathrm{J}$ & $1,8.10^{3}$ & $3,2.10^{3}$ & ausente & 43 & 9,2 \\
\hline \multicolumn{6}{|c|}{ COLETA 3} \\
\hline $\mathrm{K}$ & $2,7.10^{1}$ & $9,6.10^{3}$ & ausente & ausente & ausente \\
\hline B & $5,7.10^{3}$ & $2,5.10^{4}$ & ausente & 43 & 43 \\
\hline A & $6,4.10^{3}$ & $4,2.10^{3}$ & ausente & ausente & ausente \\
\hline $\mathrm{G}$ & ausente & $1,5.10^{3}$ & ausente & ausente & ausente \\
\hline $\mathrm{D}$ & ausente & $1,3.10^{2}$ & ausente & ausente & ausente \\
\hline
\end{tabular}


Tabela 1: Determinação de bactérias aeróbias mesófilas, bolores e leveduras, Salmonella sp., coliformes totais (CT) e coliformes termotolerantes (CTT) nas amostras de polpas de açaí.*

(Conclusão)

\begin{tabular}{|c|c|c|c|c|c|}
\hline \multicolumn{6}{|c|}{ COLETA 4} \\
\hline $\mathrm{L}$ & $5,0.10^{2}$ & $7,0.10^{3}$ & ausente & 23 & ausente \\
\hline $\mathrm{H}$ & ausente & $3,0.10^{2}$ & ausente & ausente & ausente \\
\hline M & ausente & $4,3.10^{2}$ & ausente & 3,6 & ausente \\
\hline $\mathrm{C}$ & ausente & ausente & ausente & ausente & ausente \\
\hline K & ausente & $7,3.10^{3}$ & ausente & ausente & ausente \\
\hline \multicolumn{6}{|c|}{ COLETA 5} \\
\hline $\mathrm{L}$ & $3,5.10^{2}$ & $4,7.10^{1}$ & ausente & 23 & ausente \\
\hline $\mathrm{N}$ & ausente & $3,9 \cdot 10^{1}$ & ausente & ausente & ausente \\
\hline M & $7,8.10^{2}$ & ausente & ausente & 23 & ausente \\
\hline G & ausente & ausente & ausente & ausente & ausente \\
\hline D & ausente & ausente & ausente & ausente & ausente \\
\hline \multicolumn{6}{|c|}{ COLETA 6} \\
\hline M & $1,4 \cdot 10^{3}$ & $4,7.10^{2}$ & ausente & ausente & ausente \\
\hline $\mathrm{F}$ & $1,3 \cdot 10^{3}$ & ausente & ausente & ausente & ausente \\
\hline G & ausente & ausente & ausente & ausente & ausente \\
\hline $\mathrm{N}$ & ausente & $3,4.10^{2}$ & ausente & ausente & ausente \\
\hline A & ausente & $6,3 \cdot 10^{2}$ & ausente & ausente & ausente \\
\hline Padrão & $* * *$ & $5,0.10^{3}$ & ausência & $* * *$ & $10^{2}$ \\
\hline
\end{tabular}

*Os valores em negrito são de contagens superiores à permitida pela legislação, para polpas de açaí congeladas.

** As letras representam as açaiterias/sorveterias onde foram feitas cada coleta.

*** Não há limite estabelecido na legislação, para polpas de açaí congeladas.

Recentemente, alguns artigos científicos sobre a qualidade microbiológica de polpas de açaí e/ou seus derivados têm sido publicados. Jones e Lemes (2014) relataram um estudo feito em Itajubá, Sul de Minas Gerais, e observaram que 83,3\% das embalagens à granel estavam impróprias para o consumo, concluindo que mesmo em polpas pasteurizadas, a contaminação pode acontecer, provavelmente pela manipulação da embalagem.

Dos Santos et al. (2016) relataram que 50\% (10) das 20 amostras de polpa de açaí coletadas em diferentes pontos da cidade de São Paulo/SP estavam impróprias para o consumo, podendo oferecer riscos à saúde dos consumidores. Marinho et al. (2018) analisaram 10 amostras de polpas de açaí congeladas em São Luís/MA e observaram que todas amostras estavam contaminadas, indicando falhas no processo de manipulação dos alimentos por partes dos vendedores. Mello e Resende (2018) avaliaram a qualidade microbiológica de 15 amostras de vitaminas de açaí comercializadas na região do Barreiro, Minas Gerais, e concluíram que 13 amostras $(86,66 \%)$ estavam impróprias para o consumo. 


\section{CONCLUSÃO}

A maioria das polpas de açaí avaliadas (70\%) estava dentro dos padrões da legislação para todos os microrganismos avaliados e $30 \%$ estavam fora dos padrões, por apresentarem contagem de bolores e leveduras acima dos limites estabelecidos. Os resultados indicam falhas em alguma etapa da produção, processamento ou manipulação do produto nos estabelecimentos que apresentaram amostras insatisfatórias. Nestes estabelecimentos em que foram encontradas amostras fora dos padrões, torna-se fundamental verificar as possíveis causas, a fim de se evitar doenças decorrentes da ingestão da polpa de açaí congelada.

\section{AGRADECIMENTOS}

Ao Programa PAPq/UEMG, pela bolsa de Iniciação Científica concedida.

\section{REFERÊNCIAS}

ALMICO, J, D.; FERREIRA, I. M.; RAMOS, G. D.; OLIVEIRA E SILVA, A. M.;

CARVALHO, M. G. Avaliação da qualidade microbiológica, físico-química e química de polpas de açaí (Euterpe oleracea Mart) pasteurizadas congeladas comercializadas em Aracaju-SE.

Revista Brasileira de Higiene e Sanidade Animal, v. 12, p. 156-168, 2018. Disponível em: < http://www.higieneanimal.ufc.br/seer/index.php/higieneanimal/article/view/439 > Acesso em: 17 mar. 2020.

AMERICAN PUBLIC HEALTH ASSOCIATION. Standard Methods for the Examination of Water and Wastewater. 22 ed. Washington: APHA, 2012.

BRASIL. Ministério da Agricultura Pecuária e Abastecimento (MAPA). Instrução Normativa ${ }^{\circ}$ 1 de 07 de janeiro de 2000. Aprova o Regulamento técnico geral para fixação dos padrões de identidade e qualidade para polpa de fruta. Diário Oficial [da] República Federativa do Brasil. Brasília, DF, 10 de jan. 2000. Seção 1, no 6, p. 54-8. Disponível em: <

https://ibravin.org.br/admin/arquivos/leis/1456251935.pdf > Acesso em: 17 mar. 2020.

BRASIL. Ministério da Saúde. Agência Nacional de Vigilância Sanitária. Resolução RDC nº 12, de 02 de janeiro de 2001. Regulamento técnico sobre padrões microbiológicos para alimentos. Diário Oficial da República Federativa do Brasil, Poder Executivo, Brasília, 10 jan. 2001. Disponível em:

<http://portal.anvisa.gov.br/documents/33880/2568070/RDC_12_2001.pdf/15ffddf6-3767-4527bfac-740a0400829b > Acesso em: 17 mar. 2020.

CAYRES, C. A.; PEREIRA, K.S.; PENTEADO, A L. Qualidade microbiológica de açaí industrializado. Higiene Alimentar, v. 31, p.134-138, 2017. Disponível em: < https://ainfo.cnptia.embrapa.br/digital/bitstream/item/171620/1/2017AP60.pdf > Acesso em: 17 mar. 2020. 
CEDRIM, P. C. A. S.; BARROS, E. M. A.; NASCIMENTO, T. G. Propriedades antioxidantes do açaí (Euterpe oleracea) na síndrome metabólica. Brazilian Journal of Food Technology, v. 21, p. 1-7, 2017. Disponível em: < http://www.scielo.br/pdf/bjft/v21/1981-6723-bjft-21e2017092.pdf $>$ Acesso em: 17 mar. 2020.

DOS SANTOS, B. A.; CAMPOFIORITO, M .C M.; PINTO, J. L. F. et al. Análise microbiológica de polpas de açaí comercializadas na cidade de São Paulo. Rev. Bras. Anal. Clin., v. 48, p.53-57, 2016. Disponível em: < http://www.rbac.org.br/artigos/analisemicrobiologica-de-polpas-de-acai-comercializadas-na-cidade-de-sao-paulo/ > Acesso em: 17 mar. 2020.

ETO, D, K.; KANO, A. M.; BORGES, T. M. R.; BRUGNARO, C.; CECCATO-ANTONINI, M. R.; VERRUMA-BERNARDI, M. R. Qualidade microbiológica e físico-química da polpa e mix de açaí armazenada sob congelamento. Rev. Inst. Adolfo Lutz, v. 69, p. 304-310, 2010. Disponível em: < https://pdfs.semanticscholar.org/a954/71ac0ae183dad4290973aa6a4236c5e0e723.pdf $>$ Acesso em: 17 mar. 2020.

FARIA, M.; OLIVEIRA, L. B. D.; COSTA, F. C. Determinação da qualidade microbiológica de polpas de açaí congeladas comercializadas na cidade de Pouso Alegre - MG. Alim. Nutr., v. 23, p. 243-249, 2012. Disponível em: < http://servbib.fcfar.unesp.br/seer/index.php/alimentos/article/view/1800/1800 > Acesso em: 17 mar. 2020.

FORSYTHE, S. J. Microbiologia da segurança alimentar. Porto Alegre: Artmed. 2002. 424 p.

FRANCO, B. D. G. M; LANDGRAF, M. Microbiologia de alimentos. São Paulo: Atheneu, 1996, 182p.

JONES, L. C.; LEMES, R. M. L. Análise microbiológica de polpas de açaí comercializadas em uma cidade do sul de Minas Gerais. Revista da Universidade Vale do Rio Verde, v. 12, p. 601608, 2014. Disponível em: <

http://periodicos.unincor.br/index.php/revistaunincor/article/view/1509/pdf_239 > Acesso em: 17 mar. 2020.

MARINHO, S.C.; MOUTA, A. R. N.; RABÊLO, H. P. S. M.; SILVA, G. M.; FURTADO, J. G. C. Condições microbiológicas de polpas congeladas de açaí comercializadas em mercados públicos de São Luís - MA . J. Health Conect., v. 2, p. 44-59, 2018. Disponível em: < http://periodicos.estacio.br/index.php/journalhc/article/view/4101/2153 > Acesso em: 17 mar. 2020.

MELLO, C. N.; RESENDE, J. C. P. Avaliação microbiológica de vitaminas de açaí Comercializadas na região do Barreiro, Minas Gerais. Sinapse Múltipla, v. 7, p. 27-37, 2018. Disponível em: < http://periodicos.pucminas.br/index.php/sinapsemultipla/article/view/16425 > Acesso em: 17 mar. 2020. 
MOURA, E. G. R. Composição nutricional e práticas higiênico-sanitárias na produção de açaí na tigela: diagnóstico e intervenção. 145 f. Dissertação (Mestrado) Universidade Federal de Goiás, Faculdade de Nutrição, 2014.

PEREIRA, J. M. A. T. K; OLIVEIRA, K .A. M.; SOARES, N. F. F.; GONÇALVES, M. P. J. C.; PINTO, C. L. O.; FONTES, E. A F. Avaliação da qualidade físico-química, microbiológica e microscópica de polpas de frutas congeladas comercializadas na cidade de Viçosa-MG. Alim. Nutr., v.17, p. 437-442, 2006. Disponível em: < http://servbib.fcfar.unesp.br/seer/index.php/alimentos/article/view/301/292 > Acesso em: 17 mar. 2020.

RIZZO-BENATO, R. T.; GALLLO, C. R. Comparação da eficiência dos caldos Escherichia coli e caldo verde brilhante lactose bile na enumeração de coliformes termotolerantes em leite e sorvete de massa. Revista do Instituto Adolf Lutz, v. 66, p. 18-25, 2007. Disponível em: < http://periodicos.ses.sp.bvs.br/scielo.php?script=sci_arttext\&pid=S007398552007000100003\&lng=pt\&nrm=iso $>$ Acesso em: 17 mar. 2020.

ROGEZ, H. Açaí: preparo, composição e melhoramento da conservação. $1^{\text {a }}$ ed. Belém: Edufpa; 2000. p. 313.

SILVA, N; JUNQUEIRA, V. C. A.; SILVEIRA, N. F. A.; TANIWAKI, M. H.; SANTOS, R. F. S.; GOMES, A. R. Manual de Métodos de Análise Microbiológica de Alimentos e Água. Livraria Varela, ed. 4, São Paulo, 2010. 